\title{
New Emerging Issues about Guidance and Counselling in an Accreditation of Prior and Experiential Learning Process
}

\author{
Pierre-Yves Sanséau ${ }^{1} \&$ Sandrine Ansart ${ }^{1}$ \\ ${ }^{1}$ Grenoble Ecole de Management, France \\ Correspondence: Pierre-Yves Sanséau, Grenoble Ecole de Management, Department People, Organizations and \\ Society, 12 rue Pierre Sémard - 38003 Grenoble Cedex - France. E-mail: pierre-yves.sanseau@grenoble-em.com \\ Received: October 31, 2013 \\ Accepted: January 21, 2014 \\ Online Published: January 22, 2014 \\ doi:10.5430/ijhe.v3n1p110 \\ URL: http://dx.doi.org/10.5430/ijhe.v3n1p110
}

\begin{abstract}
The aim of this research is to examine special features of guidance and counselling roles in a process of accreditation of prior and experiential learning (APEL). More specifically, we have two main goals: to identify any possible distinctive feature of guidance and counselling provided during a skills-oriented APEL procedure; and to highlight any skills that actors involved in the guidance process may need to develop. In order to collect the data, we used semi-structured interviews with a sample of twenty APEL guidance counsellors who had all been involved in APEL guidance and counselling in the higher education sector in a Business School setting in France. The results of the research underline three central issues: (i) the distinctive nature of APEL guidance and counselling compared to other guidance and counselling on offer in higher education, (ii) a specificity arising on the one hand, from the focus of the analysis - the professional and personal experience of the APEL candidate - and, on the other hand, from the skills-oriented benchmark and the objectives of diplomas awarded by the Business Schools, (iii) similarities to coaching evident in the description of some of the skills needed for this type of guidance and counselling. We then analyse the specific nature of the APEL process, which entails self-examination and self-analysis and we discuss the fact that the core skills required for APEL guidance and counselling could be similar, in various aspects to those needed for coaching.
\end{abstract}

Keywords: APEL, Guidance, Counselling, Business schools, Self-examination, Coaching, France

\section{Introduction}

In France, law $n^{\circ} 2002-73$ of 17 January 2002 and its implementing decrees, also known as the "law on social modernisation", provides for the possibility of obtaining a full diploma or course units through a process of accreditation of prior and experiential learning (APEL). Any candidate involved in an APEL process must be offered guidance and counselling, which they are free to accept or decline. This guidance and counselling is designed to help the candidate prepare their APEL eligibility application and to defend it before the validation panel.

«VAE » for Validation des Acquis de l'Expérience is the official expression to qualify the APEL process in France. We can underline that the meaning and the content of the French and English expressions are different. In French, one speaks of validation of "acquired dimensions" issued from the experience (as a validation allowing the obtaining of a full diploma) as in the English language, it's about accreditation of experiential learning (accreditation of prior and experiential learning). French practices show that VAE can validate various things depending of the VAE orientation decided by the validating institutions: knowledge, skills, competencies, etc. In fact, each country has developed its own APEL specificities in term of content and final objectives linked to its professional, educational context and priorities. In most cases, the main difference between knowledge and skills issued from experience compared to the one issued from courses in that it's linked to practical experience and it is not academic oriented. In this paper, when we talk about VAE, we use the "APEL" expression for our English reading audience (Colardyn \& Bjornavold, 2004; Duchemin \& Hawley, 2010; Pougeta \& Osborne 2004).

Based on analysis of the literature in this field, we have highlighted the need to carry out a more in-depth study of the nature and specificities of this guidance and counselling role (Lam \& Hui, 2010; Talbota, 2009). While initial studies and analyses have focused on the context of French Higher Education (especially University education) and the characteristics of APEL guidance at this level, there is visibly no research into the implementation of Business 
School APEL processes that are skills-oriented, rather than knowledge-based (Ancel \& Nkeng, 2008; Henry, 2008; Le Squére \& Le Scouiller, 2006).

Business Schools seem to have chosen to use a skills-oriented APEL process because they state that their courses are more vocationally-oriented than those taught in universities (Sanséau \& Ansart, 2010). It should be noted that the higher education sector in France includes two types of institution: university establishments and Grandes Ecoles which mainly provide teaching in the fields of engineering (Ecoles d'ingénieur) and management (Ecoles de commerce, also referred to as 'Business Schools'). These Business Schools offer a wide variety of diplomas from the bachelor to the doctoral levels, are very focused on the selection and the academic level of their students and have traditionally played a powerful role in the re-production of the French elite. Studying in a Business School is considered to be less theoretical oriented than at the university, with a more practical approach of teaching, and with strong links with the companies and the business environment.

This prompts discussion on which type of APEL guidance and counselling will be needed mobilizing a skills-based approach that hinges on skills-based frames of references. Our research set out with a two-fold objective: to identify and analyse the nature of the APEL guidance and counselling delivered in Business Schools, and to pinpoint the skills that are essential to a skillset-based APEL guidance process.

In the first section, we present a review of existing literature in the field of APEL guidance and counselling. This enables us, in section two, to set the research in context and to present the methodology used. In sections three and four we present the results of the research and offer our analysis and discussion.

\section{Literature review}

\subsection{APEL guidance and counselling: definitions and approaches}

Since 2002, a new function and a new role have progressively emerged in the French training sector: APEL guidance counsellor. This role, created by the 2002 law on social modernisation and its implementing decrees, has progressively developed and taken shape as the APEL system has been trialled and developed. Although in higher education, guidance for students during initial or further training has always been provided by teaching staff (supervision of work placements, dissertations and theses, tutoring), APEL guidance and counselling has attracted particular attention. Since 2002, many specialists, particularly in the education sector, have identified the specific nature of APEL guidance and counselling and the need to focus more closely on the role of the APEL guidance counsellor, the scope of his action, the specific characteristics of this activity, the requisite skills and the allied difficulties (Corradi et al., 2009; Davies, 2006; Haeringer, 2006; Le Squére \& Le Scouiller, 2006; Valk, 2009).

At this point, we have to underline that the French APEL field focused much more on the role of the APEL guidance counsellor than on the models of guidance and counselling approaches and its relevant methods. In fact, guidance and counselling appear as a large nebula including various practices. One speaks about counselling, coaching, mentoring, sponsoring, studying companion, mediation, etc. A quite dense literature introduces the differences and the similarities between these models of guidance and counselling approaches (Garvey, 2004; Garvey \& Alred 2000; Rhodes \& Beneicke, 2002; Roberts \& Jarrett, 2006). The stakes around the mobilized methods are also evocated. One usually distinguishes the psychoanalytical approaches issued from Freud and Jung streams from more operational approaches oriented around problem solving issues (Barning \& Higgins, 2007). The French analysts of the French APEL guidance and counseling issues underline roles in fact very close to coaching and counselling and distant from tutoring and mentoring. Considering tutoring and mentoring, the notions of education and reproduction of a model are much more present.

The definitions found in the literature enable us to identify several APEL guidance and counselling-related roles and to highlight their specific characteristics.

Mayen (2004) identifies two areas of action underpinning the guidance and counselling role: (1) first of all, get candidates to give their expectations of the guidance process, the value they ascribe to their experience, then get them to describe their experience (career path, duties and responsibilities, skills employed); (2) explain and negotiate the "guidance contract" in tandem with the candidate.

Lainé (2004) identified four main stages in the process of partnership APEL guidance and counselling: contact between the candidates and the guidance counsellor(s), retracing the candidates' career paths, interviews during which the candidates' activity focuses are described and analysed, and writing up the application files, during which the counsellor theoretically takes a back seat. 
Besides defining the different stages and phases of the guidance and counselling process, how can this organically-emerging work-in-progress be defined?

APEL guidance and counselling can, in its initial stages, be regarded as a form of assistance. Here we are referring to support given to the candidate to help them shortlist and classify their professional experience (Le Squére \& Le Scouiller, 2006), or "to enable the candidates to detach themselves from the obvious and reflect upon what they do and know" (Henry, 2008, p. 59). In the same vein, Ancel \& Nkeng (2008, p. 39) define APEL guidance and counselling as "assistance given to the candidate by a guidance counsellor to help them rebuild a picture of their professional experience, express their experiential learning and formalise it". The notion of "support" is also present and should be expressed as such in order to alleviate the candidate's doubts, difficulties and mental blocks without slipping into the role of psychotherapist (Lainé, 2004).

\subsection{APEL guidance counselling in higher education}

APEL guidance counselling in higher education is a highly complex position, as the role that has to be played in order to ensure that the candidate gets to the panel stage is multi-facetted. Clearly, in these terms, the role is neither simple, nor easily accessible. According to Vial \& Mencacci (2004), APEL at university hinges on two critical preconditions.

The first is that APEL at university level really needs to make provision for a "mediator" or pedagogical guidance counsellor who positions himself/herself at the interface between candidate and director of studies for the diploma targeted.

The second precondition - a decisive one in theory - relates to the need for the guidance counsellor to receive specific training. As well as possessing the skills of an adult trainer, it would appear to be essential for a guidance counsellor working in a university to be able to distinguish between informal experiential knowledge and academic knowledge. The counsellor needs to be able to conduct an interview, be comfortably able to get the relevant director of studies to specify the frames of reference for the diploma in question, without losing sight of the limits of the tool. The counsellor must have knowledge of the APEL assessment model, as well as of the specificities of the process and the potential expectations of the validation panel.

\section{Research focus and methodology}

\subsection{An issue focus grounded in higher education}

The focus of the research presented in this article stems from two central observations relating to the APEL guidance and counselling process in the higher education sector.

Tutors often appear to have been "appointed" to the role of APEL guidance counsellor. It would seem that their experience of guidance and counselling in other areas predisposes them as potentially "good" APEL guidance counsellors. Vial and Mencacci (2004) argue that this guidance role is in some respects (assessment role) very close to that provided by dissertation or thesis supervisors and would not therefore require university staff to acquire new competencies.

However, we have identified a situation which is specific to APEL guidance counselling or APEL counselling training in Business School-type higher education establishments that use a skills-based APEL approach and skillset benchmarks. APEL guidance and counselling does not share the same tenor, the same role or the same objectives, nor does it entail the same hands-on experience as the kind of guidance and counselling that teaching staff have traditionally been used to giving (supervision of dissertations, vocational or academic theses, overseeing work placements), whether in the short-, medium- or long-term.

This situation, which appears contradictory, led us to propose two research focuses that form the backbone of the issues we address.

$1^{\text {st }}$ proposal: APEL guidance and counselling in general, and more specifically within the framework of a skillset benchmark approach to APEL, is a process that is different from well-established guidance and counselling processes (dissertations, theses, etc), which teachers in higher education are familiar with.

$2^{\text {nd }}$ proposal: APEL guidance and counselling within the framework of a skillset benchmark approach in higher education requires that teachers, in order to successfully complete the process, are able to adopt new attitudes and acquire new skills. 
The aim of this research is thus two-fold: (i) to identify any possible distinctive feature of guidance and counselling provided during a skills-oriented APEL procedure, ii) to pinpoint any skills that actors involved in the guidance process may need to develop.

\subsection{Research methodology and context}

Our main goal in this research was to have a view and better understanding of a phenomena (guidance and counseling in an APEL process based on a skills-oriented APEL procedure and its related mobilized skills) with the eyes of the APEL guidance counselors, to emphasize the context, and at the end to explore a new field of knowledge (APEL guidance and counselling in Business schools). We didn't plan to measure frequencies but to examine properties of a certain activity and situations. To do so, we opted for a qualitative research method (Denzin, 2000). According to Creswell (1998), qualitative research is the research process whereby researchers build up a complex, holistic framework by analyzing narratives and observations, conducting the research work in the habitat.

In order to collect the data, we used semi-structured interviews. The sample comprised 20 APEL guidance counsellors who had all been involved in APEL guidance and counselling on at least two occasions in the higher education sector in a Business School setting.

The designed questionnaire was focusing on five areas in direct relationship with the research proposals:

$1^{\text {st }}$ research proposal: Characteristics and nature of guidance and counseling in an APEL process based on a skills-oriented APEL framework

Area 1: perception of APEL guidance and counseling

Area2: specific characteristics of APEL guidance and counseling

$2^{\text {nd }}$ research proposal: Identification of potential needed skills for the APEL guidance counselors

Area 3: assessment of the nature of the service provided (assistance, evaluation, catalyst, eye-opener)

Area 4: skills used by the guidance counselor

+ Area 5: Potential recommendations

This research was conducted in France in 2009 in a Business School-type higher education institution specialising in management (study area number 34, ISCE (Note 1) 1997). The diplomas awarded by this institution are classified under levels 5 and 6 of ISCE 1997 (Note 2).

\section{Research results}

The gathered data has been analyzed through a coding process. This qualitative analysis of the interviews highlighted first and foremost the extent to which APEL guidance and counselling are dependent on a triangle of factors: the requested deliverable/the nature of the benchmark for the evaluation/the stance the candidate needs to adopt. Moving ahead, a further three main elements, which are detailed in the following sections, can be drawn from the analysis of the research results:

- It would appear that the specific nature of APEL guidance and counselling compared to other guidance and counselling offered in higher education, and more specifically in Business Schools, is a critical factor, due precisely to the very fact that the activity is different in nature;

- The specific characteristics of the guidance and counselling appear to stem, on the one hand, from the focus of the analysis - the professional and personal experience of the APEL candidate - and, on the other hand, from the skills-oriented benchmark and the objectives of diplomas awarded by the Business Schools;

- The ties to coaching voiced to describe some of the skills needed for this type of guidance and counselling.

\subsection{Different processes requiring different guidance and counselling skillsets}

In higher education, there are two types of activities tied to guidance and counselling that are available to students in parallel to course teaching and on which reports are written. They are designed to validate learning in a professional environment (the work placement journal and the related work placement report) or to validate a student's ability to analyse a situation framing a specific topic with a more theoretical than practical perspective concerning the French educational system. (dissertation). In all instances, interviewees assert that the nature of the focus of the analysis and the analysis required differ in a number of ways - and significantly - from that found in an APEL process. Consequently, the candidate, too, must adopt a different stance, which will clearly impact on the guidance and counselling provided. 
The characteristics of a dissertation appear to be those most far removed from the characteristics of an APEL report. The aim of a dissertation is to assess the student's ability to express themselves on a specific topic: knowledge is conveyed first and foremost through a reasoned analysis.

Table 1. Comparison of the focus and objectives of the dissertation, the work placement report and the APEL report

\begin{tabular}{|c|c|c|c|c|}
\hline & Dissertation & $\begin{array}{l}\text { Work placement } \\
\text { report }\end{array}$ & APEL report & \\
\hline & & & $\begin{array}{l}\text { Based on knowledge } \\
\text { benchmark }\end{array}$ & $\begin{array}{l}\text { Based on a skillset } \\
\text { benchmark }\end{array}$ \\
\hline $\begin{array}{l}\text { Focus of } \\
\text { the analysis }\end{array}$ & $\begin{array}{l}\text { Theoretical or } \\
\text { practical situation } \\
\text { which poses a } \\
\text { problem, and is } \\
\text { analysed via a } \\
\text { research-based } \\
\text { focus structure }\end{array}$ & Experience & Experience & Experience \\
\hline $\begin{array}{l}\text { Type of } \\
\text { analysis } \\
\text { required }\end{array}$ & $\begin{array}{l}\text { Situational analysis } \\
\text { (knowledge } \\
\text { experience) and } \\
\text { mainly based } \\
\text { knowledge or a } \\
\text { perspective relative } \\
\text { to knowledge }\end{array}$ & $\begin{array}{l}\text { A perspective of the } \\
\text { activity relative to } \\
\text { knowledge acquired } \\
\text { during training and a } \\
\text { more in-depth } \\
\text { analysis on a } \\
\text { specific point } \\
\text { (usually structured } \\
\text { around a specific } \\
\text { research focus) }\end{array}$ & $\begin{array}{l}\text { Prove that the } \\
\text { knowledge set out } \\
\text { in the benchmark } \\
\text { standard has been } \\
\text { acquired as a result } \\
\text { of being used in the } \\
\text { exercise of a } \\
\text { professional activity }\end{array}$ & $\begin{array}{l}\text { Prove that the skills } \\
\text { set out in the } \\
\text { benchmark standard } \\
\text { have been } \\
\text { acquired as a result } \\
\text { of being used in the } \\
\text { exercise of a } \\
\text { professional activity }\end{array}$ \\
\hline $\begin{array}{l}\text { Role of } \\
\text { experience } \\
\text { in the } \\
\text { analysis }\end{array}$ & $\begin{array}{l}\text { To illustrate } \\
\text { arguments }\end{array}$ & $\begin{array}{l}\text { Starting point which } \\
\text { the trainee should } \\
\text { use to reflect upon } \\
\text { the specific nature of } \\
\text { practical } \\
\text { implementation in } \\
\text { relation to core } \\
\text { knowledge }\end{array}$ & Main focus & Main focus \\
\hline $\begin{array}{l}\text { Positioning } \\
\text { of the } \\
\text { candidate }\end{array}$ & External & $\begin{array}{l}\text { External }+ \text { elements } \\
\text { of perception of } \\
\text { experience }\end{array}$ & $\begin{array}{l}\text { Fairly external } \\
\text { because positioning } \\
\text { in relation to } \\
\text { knowledge } \\
\text { stemming from an } \\
\text { institutional } \\
\text { framework }\end{array}$ & $\begin{array}{l}\text { Alternating between } \\
\text { internal and } \\
\text { external, } \\
\text { self-examination, } \\
\text { self-analysis }\end{array}$ \\
\hline
\end{tabular}

Work placement supervision and the allied work placement report can be considered to be more akin to the exercise that APEL candidates are engaged in. The similarity lies in the focus of the analysis: experience, which can vary in length from case to case. It is the exercise of a professional activity that leads to a report being written - but that is where the similarity ends.

Beyond that, each type of analysis entails a very different stance:

- The aim of the work placement report is to examine the experience in the light of the knowledge imparted during the course modules, and in many cases to take one specific point on which to build an analysis (which often has a particular focus); 
- The aim of the APEL report is for the candidate to be able to prove they possess certain knowledge or skills as a result of their experiential learning, the different posts they may have held, and the different missions they may have carried out over the course of their career.

These distinctions between the APEL process and other types of activities for which reports have to be written in Business Schools refer back to the link between guidance and counselling and the triangle of factors - requested deliverable, standard benchmark for the evaluation, stance the candidate needs to adopt. Given the specific nature not just of the APEL process but also the skills-oriented benchmark, the candidate's stance is essentially specific:

- taking career path and life path - and to some extent personality - as the focus of analysis;

- developing an ability to analyse one's own work practices;

- $\quad$ allying this with a critical mindset so as to project experiential learning into the future;

- expressing this analysis of personal experiential learning and formalising it in writing;

- $\quad$ and developing the right level of confidence in oneself, one's experience and one's experiential learning.

The stance needed to successfully complete the APEL process highlights the distinct nature of the guidance and counselling required. As regards the work placement report, the guidance counsellor must first and foremost help the student to examine his/her experience in order to be able to choose an aspect that is relevant to the knowledge acquired during his/her training. This also entails methodological aspects, but the students have often encountered these - albeit less comprehensively and as part of a less in-depth analysis - during the various formative and informative evaluation processes that litter the course modules. The guidance counsellor, however, is usually a specialist in this field and therefore very familiar with the knowledge most required during the work placement.

4.2 A specific and predominant role for experience in a skillsets-oriented APEL process integrating the objectives of Business School diplomas

The candidate's experience, due to the position it occupies and the fact that it is the very focus of the observation, is largely what shapes APEL guidance and counselling. Being able to articulate personal experience is already a complex process, and analysing it from a skills-base perspective only increases the level of complexity.

By talking about his experience, it is the individual - and therefore the candidate himself - who must sift through their own experiential learning. The guidance counsellor's mission has to contend with a major difficulty: to give guidance to a candidate who has to comprehend their own experience, which they initially see as banal (how do you address the 'obvious', the day-to-day behaviours?)

Comprehending one's own experience is a specific exercise. Unlike a candidate who is writing a dissertation or a work placement report, it is not easy for a candidate to go back over his/her past for the first time. The candidate is unaware of the knowledge, know-how and soft skills he/she uses to perform his/her job. The guidance counsellor must immerse the candidate in a process of recollection so that they can recall their past experience, and then provide them with a methodology enabling him/her to self-ask the right questions and establish a two-way iterative process: between himself/herself as an observer and himself/herself as the focus of the observation on the one hand, and between his/her professional experience and the standard benchmark they need to meet. Guidance counsellor resort to making reference to the overall process that the exercise is part of, in order to distinguish these 'sub-processes': one is the training on work placement reports and the dissertation, the other is the process of accrediting experiential learning for the APEL report.

The complexity increases when the exercise is based on a skills-based benchmark standard for diplomas awarded by Business Schools. Although an APEL process always involves looking back at past experience, it would appear to entail a greater emotional involvement when it is skills-based rather than knowledge-based. It is easier to come to terms with not knowing something (lack of knowledge) than not knowing how or in what way to do something (lack of skills). "A candidate who does not know something" finds justification by claiming they have not learnt that knowledge but that he can make up for this by bridging the gaps in his knowledge. There is little challenge to personal ability. A candidate who does not have the requisite skills questions will be quicker to stop and question their professional practices, his/her professionalism, or even himself/herself as an individual.

\subsection{APEL guidance and counselling repeatedly likened to coaching}

The results of the research show that the term "coaching" is often instinctively referred to when talking about the skills used by counsellors to successfully complete their missions. They also pin point some dimensions of guidance and counselling which are close to a coaching process. 
To illustrate this notion, the counsellors who were interviewed refer to:

- the term or the expression "coaching" which is part of their discourse although it had never been mentioned in the questions asked during the interviews.

- the absence of a direct training role, in the sense that there is no material associated with a branch of learning to be passed on to the candidate (concepts, analytical methods and tools, theory...);

- a process that is centred on the candidate's experience;

- a process in which the counsellor must ask questions and get the candidate to ask himself/herself questions so that he discovers for himself/herself the acquired skills from his/her experience;

- a questioning process designed to lead the candidate into adopting a stance that will enable self-analysis and self-examination;

- a process that implies that the candidate is able to discover himself and assert himself/herself as an individual that has the requisite skills "required" by the skills benchmark. These assertions lead us to reflect upon possible similarities between coaching and guidance and counselling in a skills-oriented APEL process used in higher education management schools.

\section{Analysis and discussion}

The results of the research show that APEL guidance and counselling is regarded by practitioners as being different from the guidance and counselling practices employed in higher education, including in Business Schools, but also that the skillsets required are quite distinct.

- In order to underscore the specific nature of the APEL process, which entails self-examination and self-analysis, particularly when it centres on a skills-based benchmark for management diplomas in the higher education sector;

- And to thus highlight the fact that the core skills required for APEL guidance and counselling resemble those needed for coaching.

\subsection{A key part of the APEL candidate's input involves self-examination}

Dictionary definitions of self-examination focus on "when one's conscience takes itself as the object of analysis (without any aim of acquiring speculative knowledge)". One of the main difficulties encountered by candidates - and which the APEL guidance counsellor must find solutions for - stems from the fact that the candidate has to analyse himself. The literature highlights how the candidate has to pore over his/her own past, translate his/her experience into experiential learning, and tackle a task that, although apparently straightforward, is actually deceptively sophisticated.

Two papers provide particularly relevant insight on this point: Lainé (2004), Ancel and Nkeng (2008). Both point to four stages, although they are not identical.

Excluding stages 1 (1. Establishing a contract) and 4 (4. Writing) presented by Lainé (2004), both pieces of research feature two core stages: the stage during which the candidate goes back over his career and the stage during which the candidate's activities are described and analysed. These stages epitomise the self-examination process. These core stages put forward by Ancel and Nkeng (2008) should also, in our opinion, be noted: they form a separate stage prior to self-examination (whether or not it is split into two, which in our analysis depends above all on whether the benchmark standard is knowledge-based or skills-based). While referring back to the presentation in Ancel and Nkeng (2008), we spend less time on the transition from the factual to the conceptual (clearly marked by the context of higher education and theoretical knowledge) for this third stage, than putting in prospect the activity, including its generic dimension, which is partially conceptual. (Sanséau \& Ansart, 2010).

\subsection{Guidance and counselling practices sharing overlap with coaching}

Given that self-examination is a stance that a person receiving coaching is invited to adopt, how far do APEL guidance and counselling and coaching overlap? The similarities relate mainly to the process and the stances of each protagonist (guidance counsellor and counsellee). There are varying degrees of differentiation as regards the objective and the focus of analysis.

The main similarities can be seen in the stances of the protagonists, the type of process they engage in and the relationships they forge.

In both the APEL process and coaching, the guidance counsellor is neither trainer, consultant, psychologist nor psychoanalyst: His/her aim is not to pass on knowledge, nor to give advice or engage the candidate in any sort of 
therapy. The guidance counsellor is first and foremost an eye-opener, a catalyst, a facilitator, and from time to time a trainer. He/she also has knowledge, or even experience, of the company because he/she is giving guidance and counselling to an individual in a professional context (even though, as Delivré (2004) states in his coaching categories breakdown, it is possible to focus on an issue typically associated with an individual with a view to improving his/her performance within the company).

The guidance counsellor possesses the method, the counsellee the material. In order for the counsellee to achieve his/her aim, he/she must take the initiative to engage in this type of process, rather than be coerced into it. The counsellee, however, is always the main actor in terms of production; he/she is responsible for the process, and is even its creator as regards APEL. The process implemented jointly by the counsellor and the counsellee is a co-production or a co-construction for both coaching (Bonot et al., 2009; Gyllensten \& Palmer, 2007; Rogers, 1957) and APEL (Mayen, 2004, also uses the term co-activity). This co-production entails guiding the candidate and providing varying degrees of direction (in theory, more under the APEL process than for coaching) in order to help them engage in the process of taking responsibility for himself and exploring the channels of action that will enable him to achieve his/her goals. This guiding process is based on questioning, transfers and counter-transfers. The role played by questioning, which is well established in the field of coaching, is also prevalent in APEL guidance and counselling: the explicitation interview (Mayen, 2004, Ancel \& Nkeng, 2008), descriptive analysis of the activity (Lainé, 2004), analysis of action, self-analysis of one's work.

The relationship between counsellor and counsellee hinges on shaping the terms of their contract (what the counsellor can be expected to provide, the counsellee's share of the responsibility in the final outcome of the process...) and the establishment of a trust-based relationship where it is clearly stated that the counsellor is not there to judge the counsellee. The extent of the counsellor's involvement, the varying scope and precision of the candidate's expectations and the emotional component that is usually present mean that, prior to the start of the process, the mode of interaction and the responsibilities of those involved need to be clearly established. This contractualisation component, which has been mentioned in the context of the APEL process (Lainé, 2004), is also present in the field of coaching and is usually linked to ethical principles that are deemed to be of fundamental importance.

The characteristics of the process and the stances of the protagonists are therefore very similar in both APEL and coaching. In other respects, there are differences of varying degrees. These differences lie in the objectives and the focus of the processes.

The APEL candidate has a clear objective:to produce a document which proves prior and experiential learning with a view to obtaining a diploma. The objective of the person receiving coaching is not unique and universal. It may not even have been clearly defined by him, or may even change during the process. There are in fact several definitions to coaching, which differ above all in terms of the objectives sought and the methods used. However, coaching can be defined as a method that can be used in various contexts, especially professional settings, with the aim of improving effectiveness and interpersonal relationships and providing help to adjust to change (this is justification for the importance that is ascribed to the diagnostic stage of the coaching process). Coaching is usually regarded as a process which is designed to lead a person or a team to develop an awareness of their main modes of functioning, with the aim of progressing beyond the situation which this person or team is in (Augustijnen et al., 2011; Kemp, 2008). Therefore, not only is the objective not identical, but the focus of the guidance and counselling is not the same either: as regards APEL guidance and counselling, the focus is the candidate's past experience, whereas with coaching the focus is the individual himself. Another important distinction is that the APEL process is measured against a benchmark standard, which is not the case with coaching. Thus, the APEL process does carry a certain amount of objectivity.These differences in terms of objectives and focus are indeed real, but are less marked when we look at the unexpected results of an APEL process benchmarked against a skills-based standard. These unexpected results stem from the significant changes that the candidate undergoes, which go well beyond writing a document proving one's work experience with a view to obtaining the desired diploma.

We can talk about the hidden face of the APEL process for the candidate, especially when the skills-based benchmark leads the candidate:

- to define himself/herself in terms of his skills and to construct a personal professional identity;

- often as consequence, to find a meaning to his/her career progression and to be capable of better defining what he/she wishes and does not wish to do; 
- as a result of the critical mindset that the APEL process requires him to develop, he/she builds for himself/herself a new frame of reference which evolves development capability.

Now, if we look at a number of definitions of coaching, we find this notion of building an identity, this quest for meaning and the evolving frame of reference. According to Augustijnen et al. (2011), the purpose of coaching is to enable a person to change the way in which he/she behaves, thinks and acts so as to make him/her more effective in a given context and, ultimately, to enable him/her to modify his frame of reference.

The APEL process thus brings about significant changes in the candidate - changes which are not initially part of the objectives of APEL - which are similar to the goals of coaching. The tight overlap between coaching and APEL guidance and counselling can be traced to the foundations of the interactivity between the counsellor and counsellee, the stances adopted, and the tools used.

\section{Conclusion}

In this paper we have taken a look at the components of APEL guidance and counselling that are crucial when it comes to supporting the candidate in the process of acquiring self-knowledge and recognition. We refer to the importance of the "mediator", "catalyst" and "eye-opener" role played by counsellors a highlighted in other research. Given the complexity of this key component of guidance and counselling and within the framework of current attempts to professionalise APEL counselling, suggestions need to be put forward on possible skills to target for development. Given the many similarities between APEL guidance and counselling and coaching practices, it would be a good idea to draw on these practices in order to pinpoint these skills.

One can also reflect upon what the most suitable profiles for guidance counsellors are. It would appear essential for him to be fully conversant with the requirements of the diploma targeted (so that he is in a better position to transmit and translate the benchmark standard the candidate must prove he meets), to have thorough knowledge of the regulatory framework, including definitions and links between skills, knowledge and theory, and to be able to trigger the questioning process and the methods required to enable the candidate to "rework" his experience. It would seem difficult not to endorse pro-active input from teachers from the establishment awarding the diploma in this type of APEL process. They possess most of the knowledge and skills required. Although they do not usually already possess questioning and awareness-raising skills, they should be more than capable of self-training in these skills.

Considering the development of APEL in the French education system, the actors deal with a role of guidance and counselling which involves new characteristics. APEL counsellors are experiencing roles close to coaching, which require specific skills. The interviewed counsellors did not express the view that they were completely out of their depth in this new role. However they did mention this innovation. None was fundamentally trained in these practices of counselling. It is first of all their interest in this kind of process and in fact their sensitivity to this new exercise which seems to have facilitated their involvement in this kind of counselling. One can suppose that APEL counsellors could develop some of these new skills. However will it be sufficient? How long will it take to master them? What are the needs in terms of standards, of institutionalization, in terms of required skills, implementation, and consequently of training process? Hence, the question of training for the counsellors arises.

These questionings are directly connected with other problems. First, the development of APEL in France encounters a number of difficulties which were pointed out by two reports of the French government (Besson, 2008; Merle, 2008): the number of candidates remains limited compared to the initial objectives of the legislators; information for the potential candidates is considered to be perfectible; the accompaniment of the candidates must be improved, even professionalized. The people who were auditioned spontaneously expressed their concerns about the weak adhesion of some professors to this new way of delivery of diplomas in particular at the higher education level. In this context, the training of professors in order to develop specific counselling/coaching skills for APEL raises other questions: beyond that of the cost for the organizations, such as the motivation of professors for this kind of specific training as they are already strongly involved in teaching and/or research tasks. Such investment can also be questioned considering the small number of APEL candidates. Moreover, APEL remains essentially marginal in French higher education establishments.

Secondly, these questions also have to be considered in the light of the development of learning approaches illustrated in particular by the development of experiment based approaches (problem based leaning, case studies.). These teaching approaches precisely suppose the evolution of the role of the teacher towards that of counsellor. What are the similarities with the required accompaniment for APEL? What about synergies in the development of skills? If such teaching methods and educational approaches were already developed within the educational establishments, it would then be possible to the development of training for coaching skills. These skills will then be useful for 
APEL or other teaching processes centered on the experimental approach. The challenge will be then to establish the similarities and the divergences between them. On the other hand, if these new (experiment-based) teaching methods were not so well considered by professors and academic establishments, the development of new APEL skills would not be regarded as a priority.

\section{References}

Ancel, A. \& Nkeng P. (2008). L'accompagnement : entre attention et discordance. In: L. Ben Moussi-Le Gall (Ed.). Validation des Acquis de l'Expérience - Retour d'expérience à l'Université (pp. 39-52). Paris : L'Harmattan.

Augustijnen, M.T., Schnitzer, G. \& Van Esbroeck, R. (2011). A model of executive coaching: A qualitative study. International Coaching Psychology Review, Vol. 6 No. 2.

Barner, R. \& Higgins, J. (2007). Understanding iplicit models that quide the coaching process. Journal of Management Development, vol.26, n², p 148-158. http://dx.doi.org/10.1108/02621710710726053

Besson, E. (2008). Valoriser l'acquis de l'expérience : une évaluation du dispositif de VAE. Rapport au Premier Ministre; Paris. France. Secrétariat D'Etat à la Prospective, à L'Evaluation des Politiques Publiques et au Développement de L'Economie Numérique

Bonot, J.E., Purvanova, R.K., Towler, A.J. \& Peterson, D.B. (2009). A survey of executive coaching practices. Personnel Psychology, 62(2), 361-404. http://dx.doi.org/10.1111/j.1744-6570.2009.01142.x

Colardyn, D., \& Bjornavold, J. (2004) Validation of Formal, Non-Formal and Informal Learning: policy and practices in EU Member States, European Journal of Education, 39-1, 69-89.

Corradi, C., Evans, N. \& Valk, A. (2006). Recognising experiential learning: Practices in European universities, Tartu: Tartu University Press.

Creswell, J. W. (1998). Qualitative inquiry and Research Design, Thousand Oaks: Sage.

Davis, P. (2006). Norms and regulations for the recognition of non-formal and informal learning in European universities: An overview. In C. Corradi, N. Evans \& A. Valk (Ed.), Recognising experiential learning: Practices in European universities (pp. 179-95), Tartu: Tartu University Press.

Delivré, F. (2004). Le métier de coach. Paris : Editions d'Organisation.

Denzin, N. K., Lincoln Y. S. (2000). Handbook of Qualitative Research, London: Sage Publications.

Duchemin, C., \& Hawley, J. (2010). European Inventory on Validation of Non-formal and Informal Learning 2010, Thematic Report - Validation in the Higher Education Sector. European Centre for the Development of Vocational Training.

Evans N. (Ed) (2000). Experiential Learning around the World. Employability and the Global Economy, Jessica Kinsgley Publications.

Garvey, B. \& Alred, G. (2000). "Educating Mentors", Mentoring \& Tutoring: Partnership in Learning, Volume 8, Issue 2, August, pp. 113-126. http://dx.doi.org/10.1080/713685525

Garvey, B. (2004). The mentoring/counseling/coaching debate: Call a rose by any other name and perhaps it's a bramble?, Development and Learning in Organizations, Vol. 18 Iss: 2, pp.6 - 8 . http://dx.doi.org/10.1108/14777280410519554

Glaser, B. G. \& Strauss, A. L. (1967). The Discovery of Grounded Theory: Strategies for Qualitative Research, Chicago: Aldine.

Gyllensten, K., \& Palmer, S. (2007). The coaching relationship: An interpretative phenomenological analysis, International Coaching Psychology Review, 2, 168-177.

Haeringer, A. (2006). The French APEL: Ambitious procedures. In C. Corradi, N. Evans and A. Valk (Ed.), Recognising experiential learning: Practices in European universities, (pp. 83-93). Tartu: Tartu University Press.

Henry, M. (2008). L'accompagnement, entre attention et discordance. In L. Ben Moussi-Le Gall (Ed.), Validation des Acquis de l'Expérience - Retour d'expérience à l'Université (pp. 25-38). Paris : L'Harmattan.

Kemp, T. (2008). Self-management and the coaching relationship: Exploring coaching impact beyond models and methods, International Coaching Psychology Review, 3, 32-42.

Lainé, A. (2004). D’une expérience à l'autre. Education Permanente, N¹59, june, 23-36. 
Lam, S. K., \& Hui, E. K. (2010). Factors affecting the involvement of teachers in guidance and counselling as a whole-school approach, British Journal of Guidance \& Counselling, Volume 38, Issue 2, 219-234. http://dx.doi.org/10.1080/03069881003674962

Le Squére, R., \& Le Scouiller, C. (2006). APEL Guidance and Counselling: the Birth of a New Profession. In C. Corradi, N. Evans \& A. Valk (Ed.), Recognising experiential learning: Practices in European universities (pp. 196-208). Tartu: Tartu University Press.

Mayen, P. (2004). Caractériser l'accompagnement en APEL - Une contribution de didactique professionnelle. Education Permanente, $\mathrm{N}^{\circ} 159$, june, 7-22.

Merle, V. (2008). Groupe de travail sur la validation des acquis de l'expérience. Rapport. Paris : Secrétaire d'Etat à l'Emploi, Gouvernement français.

Pougeta, M., and Osborne, M., (2004). Accreditation or validation of prior experiential learning: knowledge and savoirs in France - a different perspective? Studies in Continuing Education, Volume 26, Issue 1, 45-66. http://dx.doi.org/10.1080/158037042000199452

Rhodes, C. \& Beneicke, S. (2002). Coaching, mentoring and peer-networking: challenges for the management of teacher professional development in schools, Journal of In-Service Education, 28:2, 297-310. http://dx.doi.org/10.1080/13674580200200208

Roberts, V.Z. \& Jarrett, M. 2006. What is the difference and what makes the difference? A comparative study of psychodynamic and non-psychodynamic approaches to executive coaching, in Brunning H. (Ed.) Executive coaching. Systems-Psychodynamic Perspective, Karnac, London, 3-40.

Rogers, C.-R. (1957). The Necessary and Sufficient Conditions of Therapeutic Personality Change, Journal of Consulting and Clinical Psychology, no 21, 95-103.

Sanséau, P.-Y., \& Ansart, S. (2010). Accreditation of Prior Experiential Learning in Higher Education: A European-North American Comparison Based on the French-Mexican Cases", Journal of Systemics, Cybernetics and Informatics, Volume $8-\mathrm{N}^{\circ} 3,1-5$.

Talbota, M. (2009). Epiphany? A case study of learner-centredness in educational supervision Preview, British Journal of Guidance \& Counselling, Volume 37, Issue 2, 195-206. http://dx.doi.org/10.1080/03069880902731345

Valk, A. (2009). Recognition of prior and experiential learning in European universities, Assessment in Education: Principles, Policy \& Practice, Vol. 16, No. 1, 83-95.

Vial, M. \& Mencacci, N. (2004). Valider les acquis d'expérience à l'université : une occasion de prendre en considération les savoirs informels, Education Permanente, $\mathrm{N}^{\circ} 159$, 67-78.

\section{Notes}

Note 1. ISCE: International Standard Classification of Education

Note 2. Equivalent to level M in the European BMD Reform (Bachelor's Degree, Master's Degree, Doctoral Degree). 